\title{
Uma análise construcionista social da liberdade na educação
}

Rita de Cássia de Souza ${ }^{1}$

\section{Introdução}

O Construcionismo Social ou as "perspectivas construcionistas" podem ser consideradas como um movimento ou numa metateoria que abriga pensamentos heterogêneos, mas que têm em comum: “... uma desconfiança sobre a natureza pré-discursiva de qualquer objeto social..." (SPINK; MEDRADO; MÉLLO, 2014, p.22). Como o próprio nome indica, para o Construcionismo Social, nossas percepções do mundo são construídas socialmente através da linguagem. Esta perspectiva nos convida a alterar radicalmente nossas concepções, já que aprendemos a ver o mundo de um ponto de vista egocêntrico e autocentrado e essa não é a única forma possível. Existem outras.

Vamos abordar aqui especialmente como a concepção de self relacional proposta por Kenneth Gergen ${ }^{2}$ pode criar outras maneiras de entender a liberdade e a autonomia do ser humano. De acordo com Edward Sampson, a sociedade democrática desenvolveu a ideia de um self individualista que se relaciona diretamente com o direito ao voto.

O individualismo possessivo primeiro diz que, para votar, é preciso ser livre; segundo, que para ser livre - independente da vontade de outro - é preciso ser o dono de si mesmo. Quaisquer condições que possam afetar a propriedade pessoal do indivíduo sobre si mesmo infringiriam a liberdade e, assim, negariam a tal pessoa o direito de votar (SAMPSON, 2008, p.33, tradução nossa).

Compreende-se, desta maneira, que o eleitor precisa decidir por si mesmo, sem ser coagido ou influenciado por outros, o que nos leva a considerar as influências dos outros como negativas, pois estas nos impediriam de pensar autonomamente.

\footnotetext{
${ }^{1}$ Universidade Federal de Viçosa, Viçosa-MG, ritasouza@ufv.br.

2 O psicólogo Kenneth Gergen (1935 -...), professor emérito da Universidade de Swarthmore, nos Estados Unidos, é um dos grandes expoentes do Construcionismo Social.

Periódico Horizontes - USF - Itatiba, SP - Brasil - e020034
} 
É claro que a formulação individualista possessiva define o ideal autocontido e simultaneamente estabelece a relação negativa de eu-outro que está na raiz da visão de mundo auto-celebrativa. Para ser uma pessoa, não se pode confiar em ninguém. Em outras palavras, o individualismo possessivo postula uma relação negativa entre o eu e o outro: quanto mais o outro está envolvido na vida da pessoa, menos a pessoa está envolvida em sua própria vida (SAMPSON, 2008, p.33, tradução nossa).

Esta visão individualista tem uma série de consequências nefastas, pois nos predispõe à competição, à desconfiança em relação aos demais e até uma exploração irresponsável em relação ao meio ambiente. Num modelo competitivo de sociedade, a simples existência de uma pessoa já parece prejudicar as demais. Este individualismo e estímulo à acumulação de recursos naturais e econômicos tem ocasionado a destruição da natureza ${ }^{3}$ e uma imensa desigualdade social ${ }^{4}$. Chegamos a um extremo de individualismo em que não toleramos mais o outro, visto como um estorvo do qual queremos nos livrar.

O Outro tornou-se o Inferno. Não por ser, metafisicamente, condição necessária e limite insuperável da liberdade do sujeito, mas pela prosaica razão de que, no cotidiano, todos tornaram-se um estorvo para todos. As revoluções democrático-burguesas haviam iniciado o processo de estranhamento do outro, quando retiraram a fraternidade, do lema francês, para dar lugar à impessoalidade. Mesmo assim, os antigos laços de lealdade, amizade e fidelidade, embora expulsos da esfera pública, encontraram abrigo na esfera privada. $\mathrm{O}$ "próximo" poderia voltar a ser próximo, desde que deixasse a luz de público e se tornasse um íntimo; um familiar; um cúmplice nas relações pessoais.

No individualismo contemporâneo, a impessoalidade converteu-se em indiferença e os elos afetivos da intimidade foram cercados de medo, reserva, reticência e desejo de autoproteção. Pouco a pouco, desaprendemos a gostar de "gente". Entre quatro paredes ou no anonimato das ruas, o semelhante não é mais o próximo-solidário; é o inimigo que traz intranquilidade, dor ou sofrimento. Conhecer alguém; aproximar-se de alguém; relacionar-se intimamente com alguém passou a ser uma tarefa cansativa. Tudo é motivo de conflito, desconfiança, incerteza e perplexidade. Ninguém satisfaz a ninguém (COSTA, 1996, s.p.).

\footnotetext{
${ }^{3}$ Uma reportagem da revista Superinteressante de 2016 afirmava: "O mundo está em crise. O uso excessivo dos recursos do planeta pelos humanos está levando a Terra a uma situação de risco nunca vivenciada antes. Pela primeira vez na história, uma espécie pode ser responsável por uma extinção em massa" (ESGOTAMENTO dos recursos naturais, 2012). 4 “...26 pessoas possuem a mesma riqueza dos 3,8 bilhões que compõem a metade mais pobre da humanidade. Os dados são de estudo divulgado pela Oxfam, organismo internacional de combate à desigualdade e pobreza, durante o Fórum de Davos, que inicia nesta terça-feira, na Suíça" (OS 26 mais ricos do mundo..., 2019).
}

Periódico Horizontes - USF - Itatiba, SP - Brasil - e020034 
Aprendemos a nos perceber como indivíduos separados do demais, com uma mente completamente independente e a maior parte do conhecimento produzido, seja ele científico, de senso comum e até mesmo a nossa linguagem estão baseados nesta premissa. No entanto, para o Construcionismo Social, esta percepção foi construída socialmente e, portanto, pode ser alterada: "O conceito de pessoa como um universo autônomo e distinto, relativamente autônomo, reflete a farsa e a ilusão que é o indivíduo burguês, não sua realidade." (SAMPSON, 2008, p.3, tradução nossa).

O Construcionismo Social trabalha com a noção de self relacional ou de que somos seres relacionais (GERGEN, 2016), o que tem implicações importantes para as relações políticas, de trabalho, as investigações científicas, as atuações terapêuticas e também para os modelos educacionais. Para Kenneth Gergen, o que somos, nosso eu, nossa mente não chega nunca a ser interiorizada, individual e separada dos demais. "En efecto, todo lo que hemos definido hasta ahora como privado y separado del 'otro' es conceptualizado como inherentemente relacional, inseparable de las actividades comunes." (GERGEN, 2007, p.111). O nosso "eu" não é algo desconectado e isolado, pelo contrário, está no meio, entre, nem do lado de dentro, nem do lado de fora. Somos "entre", "com", coletivos, não indivíduos.

\footnotetext{
Criar o eu relacional não é tarefa fácil, principalmente porque as palavras que conhecemos são produto da tradição individualista. Dispomos de milhares de termos que 'tornam realidade' as condições e os conteúdos da mente individual. Podemos começar a falar, e não acabar, de nossos pensamentos, sentimentos, esperanças, sonhos, ideais... Pelo contrário, temos muito poucas palavras para descrever as relações. É como se nossa linguagem fosse enormemente rica para descrever as peças de um tabuleiro de xadrez, mas tremendamente pobre para descrever o próprio jogo (GERGEN; GERGEN, 2011, p.44, tradução nossa).
}

Como produtos e produtores de uma construção coletiva, cada relação em que participamos, cada contato que temos nos altera e altera os demais, influenciando a nossa constituição psíquica e o ambiente à nossa volta. As novas tecnologias, especialmente as TIC's, tecnologias de informação e comunicação, provocaram uma revolução na nossa forma de relacionar com o mundo e com as pessoas, pois elas aproximam diferentes e variados contextos culturais e nos transformam profundamente, já que somos, precisamente, este conjunto de relações.

Como comenta Zigmunt Bauman de um cartaz que estava nas ruas de Berlim em 1994: 
"Seu Cristo é judeu. Seu carro é japonês. Sua pizza é italiana. Sua democracia, grega. Seu café, brasileiro. Seu feriado, turco. Seus algarismos, arábicos. Suas letras latinas. Só o seu vizinho é estrangeiro." (BAUMAN, 2005, p.33). Somos, cada vez mais, múltiplos e estamos expostos a uma infinidade de tradições e valores. Essa é uma realidade absolutamente nova, pois há alguns poucos séculos atrás, de uma maneira geral, pessoas comuns dificilmente saíam de sua aldeia, de sua cidade, raramente tinham a oportunidade de conversar com alguém que tivesse outra religião, costumes e idioma. No mundo atual, cada vez mais cedo e com mais frequência, convivemos com múltiplas culturas, costumes e hábitos fazendo com que, cotidianamente, estejamos próximos - ainda que virtualmente - do que consideramos estranho, diferente ou exótico. Isso significa que, muito mais do que as gerações anteriores, precisamos aprender a lidar com esta diversidade e a infinita possibilidade de criação humana.

No modelo individualista em que nos mantemos, tendemos a temer o outro, já que o diferente pode ser visto como uma ameaça aos valores, costumes e crenças de uma determinada cultura.

\begin{abstract}
Nesse artigo, verso sobre a temática do medo que, como sabemos, é sempre suscitado pela entrada do novo, do imprevisível em nossas vidas. Por mais que busquemos nos manter afastados de determinados indivíduos ou ambientes, ainda assim não nos livraremos deste fardo. A ideia de uma vida sem medo povoa nosso imaginário, construindo uma espécie de 'delírio coletivo' que pode, em muitos casos, ter implicações desastrosas se objetivado por meio de estratégias que visam a destruição do outro (simbólica e/ou física). [...] O medo é sempre o medo do estranho e, dependendo do contexto, o estranho pode assumir várias faces. Esse ser indecifrável e sem rosto em algumas situações ganha cor, residência, idade; para que assim possamos apaziguar nossas neuroses cotidianas (BITTENCOURT, 2009, p.164).
\end{abstract}

Além de tratar da impossibilidade de nos mantermos livres do medo e das diferenças, João Batista Bittencourt questiona: “... é o estranho que produz os medos cotidianos ou são os medos cotidianos que produzem os estranhos? [...] Neste sentido, é possível pensar que os medos cotidianos são os resultados e não os resultantes." (BITTENCOURT, 2009, p.173). Essa é uma perspectiva interessante porque sugere que lidemos antes com os medos que com os estranhos, já que a diversidade é uma característica fundamental e, podemos considerar, a grande beleza da humanidade.

Periódico Horizontes - USF - Itatiba, SP - Brasil - e020034 
Justamente neste sentido, a proposta do Construcionismo Social nos convida a derrubar os muros e construir pontes, nos aproximando do que tememos e estabelecendo uma convivência respeitosa e pacífica. Dentro da perspectiva relacional, a existência do outro é fundamental para a nossa. A diversidade é um pressuposto da democracia. O oposto disso é ditadura e censura.

Propomos aqui que o que costumamos sentir como um "peso", algo que devemos suportar e com o qual temos que nos conformar, seja completamente reinterpretado. Edward Sampson afirma que, ao invés de tolerar, devemos celebrar o outro, considerando que nossa humanidade é uma construção coletiva e social.

Mas talvez a maior lição de todas, uma que transforme a mesa completamente no projeto auto-celebrável do mundo ocidental, é simplesmente que a celebração do outro está no coração da vida e experiência humanas. O outro é um co-criador vital da nossa mente, do nosso eu e da nossa sociedade (SAMPSON, 2008, p.109, tradução nossa).

O Construcionismo Social propõe a mudança de uma perspectiva individualista em que tememos o outro e exaltamos o nosso eu, nossa autonomia e individualidade para celebrar as diferenças, o outro e todas as formas de interação e convivência que nos fazem ser quem somos, seres relacionais e em profunda interdependência. Considerando esta perspectiva relacional, como podemos pensar a questão da liberdade? Até que ponto falamos por nós mesmos e ou estamos sendo "marionetes" influenciados pelo contexto, pela mídia ou por outras pessoas?

Voltamos aqui ao velho embate entre as explicações inatistas e ambientalistas para o comportamento humano. Para os primeiros, somos o resultado de nossas heranças hereditárias; para os segundos, o produto do meio ambiente. Nestes dois casos, o ser humano tem pouca ou nenhuma autonomia sobre suas ações já que estas são manipuladas por forças maiores que nem sempre ele pode controlar. A terceira via é dada por aqueles que trazem a ideia da construção. Neste caso, não se desconsidera as influências hereditárias ou ambientais para o comportamento humano, mas o sujeito é percebido como ser ativo, ou seja, capaz de interferir - com maior ou menor sucesso - nas influências que recebe. No entanto, ainda aqui a percepção é individualista. A diferença para a compreensão do ser humano como relacional, é que, neste caso, ele constrói a si mesmo - aos outros e ao meio - lidando com as influências biológicas e 
ambientais do seu contexto de maneira ativa e dinâmica, mas, fundamentalmente, de maneira integrada, coletiva, nunca solitária.

Para o Construcionismo Social, não há ser humano fora de uma integração. Até mesmo do ponto de vista biológico, somos o resultado da fusão de características paternas e maternas. Do ponto de vista psicológico, só pensamos, falamos e agimos como seres humanos porque convivemos com outros seres humanos. Toda a relação com o mundo -ainda que nos pareça interna: pensar, sonhar, memorizar- é coletiva. É impossível ser, se não houver contato com outros semelhantes. Somos a partir dos demais. Daí a ideia de ser livre, neste contexto, não significa pensar individualmente, de forma separada e desconectada dos outros. Também não há aqui uma visão de que "pensar com" significa falta de autonomia. Pensamos "com" simplesmente porque é impossível pensar só. Para pensar, precisamos de uma linguagem, de ideias, de fatos que existem fora de nós.

Se liberdade não significa pensar individual e separadamente dos demais, o que significaria então? Neste caso, compreendemos liberdade como possibilidade da divergência, de expressar opiniões que não são a da maioria, que não são dominantes num determinado contexto. Isso não significa uma capacidade ou talento individual de um sujeito excepcional. Pensar "fora da caixa" significa que há uma "caixa", há um padrão e tudo que está fora é divergente, marginal e estranho.

Tendemos a considerar estáticos aspectos da vida humana que são muito mais fluidos e dinâmicos. A cultura, os valores, as formas de existências nos dias de hoje são muito diferentes das de nossos antepassados. Além disso, é muito provável que aquilo que hoje você sustenta com convicção e certeza seja bastante diferente do que você pensava há 10, 20 anos atrás ou do que você vai pensar daqui a algumas décadas. Se você pudesse se encontrar consigo mesmo num outro período de tempo, vocês concordariam sobre temas importantes na sua vida? Vou apostar que não. As "cercas" que separam pensamentos diferentes não são intransponíveis. Nós mesmos podemos mudar de lado e alterar significativamente nossas posições. Isso talvez nos ajude a ter um pouco mais de compreensão com o outro e sua visão de mundo.

Quanto mais achamos que só uma forma de ver o mundo - a nossa - é adequada e aceitável, menos liberdade damos ao outro de existir. O outro, por mais diferente, estranho e incômodo que nos pareça, só existe porque é produto da nossa humanidade, algo pelo qual 
somos coletivamente responsáveis. Precisamos admitir que há outras formas possíveis de ser e estar no mundo, ainda que nos pareçam irracionais ou inapropriadas. Isso não significa concordar ou incentivar, significa simplesmente reconhecer e respeitar. Continuamos sempre tendo o direito de divergir e de nos opor a pensamentos que nos pareçam inadequados. O que não podemos é considerar que eles não podem existir, que precisam ser aniquilados.

Como seres sócio-histórico-culturais, nossa linguagem, nossos valores, nossos contextos nos constituem como seres únicos. Mesmo gêmeos idênticos, criados numa família e contextos muito semelhantes constroem diferentes formas de ver a vida. Buscar consenso e homogeneidade é aniquilar a beleza da diversidade humana, um intento absurdo e impossível. Entretanto, criados e educados dentro de um paradigma individualista e competitivo, é um desafio reelaborar nossa existência numa perspectiva relacional e colaborativa. A educação é fundamental neste processo e, neste sentido, vamos apresentar algumas propostas de autores construcionistas sociais.

\section{Dialogando com aqueles que não tem nada em comum}

Diálogo é essencialmente uma aventura colaborativa (GERGEN, 2015, p.123)

Gert Biesta (2004) apresenta duas formas de viver em comunidade. A primeira, a comunidade racional, reúne pessoas que se se associam justamente porque tem pensamentos e ideias similares. Neste modelo, há duas formas de se lidar com os que são estranhos, os que pensam diferente: a assimilação ou a antropofagia, que consiste em cooptar o estrangeiro e transformá-lo em um participante da comunidade e a exclusão que pode, inclusive, culminar na destruição física daqueles que são estranhos à comunidade. Nesta perspectiva não existe a possibilidade de integrar os que pensam diferente, que são, de uma forma ou de outra, eliminados e excluídos do grupo. A segunda forma de viver em comunidade seria integrando pessoas que não tem nada em comum. Isso não significa um completo relativismo em que tudo é aceito, ou em que não se possa falar sobre as diferenças ou divergências; significa criar espaços de comunicação e convivência entre desiguais. Biesta afirma que a educação tem um papel importante neste trabalho de constituir estas comunidades em que existe liberdade de ser e de 
expressar, mas isso exige uma significativa reformulação no modelo escolar conhecido, que tende a ser excludente, competitivo, individualista e colonizador.

Neste ensaio, denominamos inclusivas estas comunidades que acolhem todo e qualquer tipo de diferença.

\begin{abstract}
A inclusão é um movimento educacional, mas também social e político que vem defender o direito de todos os indivíduos participarem, de uma forma consciente e responsável, na sociedade de que fazem parte, e de serem aceites e respeitados naquilo que os diferencia dos outros. No contexto educacional, vem, também, defender o direito de todos os alunos desenvolverem e concretizarem as suas potencialidades, bem como de apropriarem as competências que lhes permitam exercer o seu direito de cidadania, através de uma educação de qualidade, que foi talhada tendo em conta as suas necessidades, interesses e características (FREIRE, 2008, p.5).
\end{abstract}

Para Sofia Freire: “A inclusão assenta em quatro eixos fundamentais: (1) é um direito fundamental, (2) obriga a repensar a diferença e a diversidade, (3) implica repensar a escola (e o sistema educativo) e (4) pode constituir um veículo de transformação da sociedade (FREIRE, 2008, p.8).

Nossa proposta aqui é apresentar o diálogo transformativo por considerarmos que ele pode ajudar neste processo de convivência entre os desiguais. Em primeiro lugar, precisamos compreender que o diálogo não é simplesmente uma conversa. Diálogo é uma forma de interação muito especial e potente, que se sustenta numa atitude de colaboração - e não competição - mantida pela curiosidade e não pelo julgamento. Conversamos muito, dialogamos pouco. Quando dialogamos, estamos verdadeiramente curiosos e interessados em ouvir as opiniões, os motivos e as razões pelas quais o outro pensa. A postura de não saber e a abertura para lidar com a incerteza e a imprevisibilidade são fundamentais neste processo:

O diálogo, em sua natureza, envolve o não-saber e a incerteza. 0 interesse sincero sobre o outro necessita não conhecer o outro, sua situação ou seu futuro com anterioridade, sem importar se o saber tem a forma de experiência prévia, conhecimento teórico ou familiaridade. Crer que se conhece a outra pessoa pode evitar o indagar e o aprender de sua unicidade. Assim, o diálogo requer uma atitude de não-saber sua direção ou o resultado final. Dado que as perspectivas mudam e o diálogo é inerentemente transformador, é impossível predizer, por exemplo, como uma história vai ser contada, os giros e voltas que possa ter sua versão aparentemente final. Assim, estas características

Periódico Horizontes - USF - Itatiba, SP - Brasil - e020034 
distinguem o diálogo como uma atividade conjunta dinâmica e generativa e como algo diferente de outras atividades de linguagem como a discussão, o debate ou as conversações informais (ANDERSON, CHAVESTE, MOLINA, 2019, p.11, tradução nossa).

Para que o diálogo aconteça, precisamos estar disponíveis a ouvir de fato o outro, considerando o seu ponto de vista, ao que Sheila McNamee define como presença radical.

Contudo, não há uma técnica, um método ou uma estratégia específica que acompanhe a presença radical. Em vez disso, há uma forma em que a pessoa se posiciona no mundo. [...] Minha posição (meu terreno) muda ao considerar a sua. Já não é meu ponto de vista e eu contra o seu ponto de vista e você. É meu ponto de vista em relação ao seu ponto de vista. Diálogo, como una forma de presença radical, fomenta a curiosidade pelo diferente, abertura à formação de novas compreensões, e um movimento que se distancia do acordo ou da competição entre perspectivas (MCNAMEE, 2015, p.4, tradução nossa).

Além da postura de profunda curiosidade, da disponibilidade de ouvir o outro e se abrir ao inesperado, apresento aqui cinco conceitos que Kenneth Gergen considera chaves para um diálogo transformativo.

\section{Ação conjunta e as origens do significado}

O significado de qualquer comportamento ou palavra é dado sempre coletivamente. "Com efeito, nenhum de nós pode fazer sentido sozinho; é na coordenação de nossas ações ou co-ação - que o significado nasce, se sustenta ou morre." (GERGEN, 2015, p.123, tradução nossa). O ditado: "Se um não quer, dois não brigam" nos ajuda a compreender esta ideia porque compreende a briga como algo relacional. Ou seja, para que algo nos irrite, nos provoque, nós temos que dar essa conotação ao comportamento ou à palavra que nos foi dirigida. Isso significa que podemos reverter completamente o sentido de uma provocação e dar um novo sentido a ela.

De acordo com a lógica da co-ação é junto que criamos um argumento, uma briga ou uma amizade. Nenhum de nós poderia fazer isso sozinho. Assim, podemos substituir o conceito de responsabilidade individual pela responsabilidade relacional. Como podemos, juntos, ser responsáveis pelos 
resultados do nosso diálogo e pelo nosso futuro relacionamento? (GERGEN, 2015, p.140, tradução nossa).

A criação de significados é colaborativa, depende de mim e do outro. Da mesma forma que uma pessoa pode tomar uma palavra ou comportamento meu como uma ofensa (ainda que não seja essa a intenção), também posso não tomar como ofensa algo que tenha por intenção me ofender. Este só se torna uma ofensa se eu o tomo como tal. Isso não significa dizer que se deva sempre ignorar ou dar outros sentidos a uma ofensa que recebemos. Não há respostas simples para eventos complexos. O que sustentamos aqui é a possibilidade de que o mesmo evento seja visto e percebido de maneiras diversas. O Construcionismo Social nos convida a explorar outros sentidos: $E$ se ignoramos a ofensa? $E$ se a tomamos como uma piada? Como um aprendizado para a vida? Como uma oportunidade para um diálogo genuíno? E se devolvermos e intensificarmos a ofensa? Quais os possíveis resultados de cada uma dessas reações? Nunca sabemos de antemão, porque, como dissemos acima, o significa não depende unicamente de nós, é uma atividade coletiva. No entanto, a atitude que tomamos nos ajuda a construí-lo. Se não somos os únicos responsáveis neste processo, tampouco podemos ignorar que nossas atitudes ajudam ou não a chegar ao destino que almejamos. E o destino que sugerimos aqui não é o da separação e da exclusão. Nossa proposta é mostrar que é possível criar espaços de coexistência e integração.

2. Pares de adjacências e cenários de diálogo

Gergen apresenta basicamente três cenários para um diálogo: o generativo, de sustentação ou degenerativo. O primeiro é marcado pela criatividade, pelo aprendizado e por sensações agradáveis, de deleite e fruição. O segundo caracteriza-se por intercâmbios normais, que mantém a vida cotidiana acontecendo de maneira previsível e ordenada. O terceiro cenário, degenerativo, define-se por reações de animosidade e quebra de relacionamentos.

Segundo o autor, quando grupos antagonistas ou de pessoas que não tem nada em comum estão juntos há uma forte tendência em se criar cenários degenerativos. “Quando nós discordamos, não é natural argumentar, ordenar e culpar? Para o construcionista, a resposta é não!" (GERGEN, 2015, p.126, tradução nossa) Existem outras formas de levar o diálogo em 
direções mais promissoras e podemos aprender a fazer isso.

Assim como no conceito anterior, nós podemos interferir nos cenários em que estamos visando torná-lo mais generativo, ou seja positivo, saudável e agradável para todos.

\title{
3. Compreensão como uma conquista relacional
}

Se todo significado é dado coletivamente, não pode ser responsabilidade de um único envolvido. Toda e qualquer ação é relacional, depende de mais de uma pessoa. Desta forma, entendimentos e desentendimentos são vias de mão dupla.

\begin{abstract}
Entender, então, é uma conquista relacional. Entender é agir de uma maneira particular e fazer com que o outro aceite essa ação como compreensão. Ou, para fazer eco às propostas anteriores, a compreensão é uma forma de coação na qual as ações são coordenadas de tal maneira que as relações prosseguem harmoniosamente. Compreensão mútua, então, é como dançar bem juntos, jogar frisbee ou remar em uma canoa (GERGEN, 2015, p.128, tradução nossa).
\end{abstract}

O silêncio e a ausência comunicam tanto quanto palavras e gritos. Mesmo numa relação "platônica", virtual ou imaginária, existe um outro, ainda que este não seja real e palpável. Quando convivemos com outros reais, estamos sempre sujeitos a desentendimentos. Um elogio pode ser tomado como ofensa, a ofensa como elogio, a proposta de romance como uma afronta e assim por diante. O sentido das palavras e atitudes não está nelas, mas na forma como são compreendidas. Nunca sabemos exatamente a intenção do outro, sempre interpretamos seu comportamento e palavras a partir de nossas experiências e expectativas. Essas interpretações podem reverter e alterar completamente o seu sentido inicial. Essa possibilidade que é raiz de muitos desentendimentos também pode ser libertadora, pois nos mostra que podemos reagir ao comportamento do outro de maneiras múltiplas e inusitadas, levando a resultados completamente diversos.

4. Pontos de escolha da conversação

Sempre podemos escolher que rumos ou que continuidade daremos às nossas conversas.

“... o que quer que seja dito não faz exigências sobre o que se segue." (GERGEN, 2015, p.129,

Periódico Horizontes - USF - Itatiba, SP - Brasil - e020034 
tradução nossa). Ou seja, há multiplas possibilidades de seguir numa conversação. Embora nos pareça óbvio que alguém que se sinta ofendido reaja e se defenda de uma acusação injusta, não é. Esta é uma forma possível de reagir, mas existem outras e cada uma delas constrói cenários muito diferentes. Embora possa pareça estranho, não é. Na verdade, é algo que já fazemos cotidianamente, muitas vezes, sem nos darmos conta. Reagimos de maneira diferente dependendo de quem nos ofendeu, do contexto em que aconteceu e do que queremos naquele momento.

No entanto, em certos conflitos e situações em que estamos emocionalmente envolvidos e feridos, nem sempre visualizamos formas diferentes de reagir. Gergen sugere, então, que se faça uma lista de possíveis reações possíveis, considerando as consequências que cada uma pode desencadear. Isso não significa que necessariamente vamos chegar a uma solução que nos agrade, pois se o significado de cada ação é coletivo, não temos controle da interpretação dos nossos atos e de como um determinado evento vai se desenvolver. O que não significa, por outro lado, que não temos nenhuma possibilidade de intervenção.

Para Gergen, sempre é possível transformar o sentido de nossas interações. Há um repertório de ações e algumas delas, mais que outras, podem conduzir a um ambiente generativo. É importante estar atento para buscar escolhas que melhorem a qualidade da relação, se queremos mantermos firmes o propósito de nos mantermos conectados e em relação com aqueles que não temos nada em comum e que são nossos antagonistas.

\section{Posicionamento social}

Os diálogos nem sempre se dão entre pessoas que estão na mesma condição de poder. Falar com um vizinho não é o mesmo que responder a uma autoridade. Em algumas situações, é evidente a desigualdade de poder, mas mesmo quando isto não é claro, nós sempre posicionamos o outro: "Em nossos modos comuns, tratando uns com os outros, estamos constantemente e sutilmente nos definindo, tratando um ao outro como um certo tipo de pessoa." (GERGEN, 2015, p.130, tradução nossa).

Preconceitos e pré-julgamentos interferem radicalmente na forma como o diálogo é estabelecido. Pessoas em posicionamentos contrários tendem a considerar seus oponentes 
como inferiores: pouco inteligentes, imorais, injustos e etc. Este tipo de posicionamento certamente leva a um cenário degenerativo e impede que se escute o outro com as suas justificativas.

Neste sentido, pode haver certos grupos de pessoas que parecem simplesmente mal-intencionados ou malvados - talvez para você esses possam ser os neonazistas, a Ku Klux Klan, a Máfia ou grupos terroristas. Esse sentimento de alienação é virtualmente um resultado inevitável da vida social (GERGEN, 2015, p.131, tradução nossa).

O diálogo só vai acontecer ao se considerar que o outro, por mais abominável que nos pareça, pode ser ouvido com curiosidade e atenção. Por isso, a postura do não saber é tão importante. Quanto mais achamos que já conhecemos o outro, menos nos abrimos para vê-lo de uma perspectiva completamente nova e diferente.

Além disso, é importante que estejamos disponíveis para manter a convivência sem buscar consenso. Para Gergen, todas as vezes que queremos que uma verdade - em geral a nossa - seja aceita por todos, criamos antagonismos e silenciamentos com as pessoas que discordam, que passam a ser indesejáveis e estranhas. Além disso, uma concepção individualista de resolução de conflitos tende a considerar que cada parte busca a melhor solução para si, em detrimento dos demais, o que gera desconfiança e temor. Considerando que a percepção individualista é opcional e não necessária, podemos buscar alternativas mais promissoras. Acreditamos que uma percepção relacional dos seres humanos abre portas que grupos com posições opostas dialoguem de maneira mais respeitosa. Assim como criamos antagonismos, podemos criar formas de conversar e seguir juntos, apesar das divergências de valores, pensamentos e crenças.

Os diálogos transformativos mudam o cenário da conversa de alienação para apreciação e, apesar dos elementos que apresentamos aqui, consideramos que não existem regras universais para este tipo de diálogo, cada processo envolve demanda criatividade e ousadia para ser construído. Conhecer algumas experiências pode nos dar pistas de como aproximar pessoas que tem percepções de mundo bastante antagônicas. Um exemplo disso é o projeto de Conversações Públicas criado em Massachussets, nos Estados Unidos, em 1989.

O objetivo das conversações não é mudar o posicionamento dos envolvidos ou alterar 
leis, mas possibilitar um momento de vivência compartilhada entre pessoas que podem ver-se como inimigas. Considerando o grande desafio que é conversar de maneira generativa com pessoas que tem valores completamente opostos, Kenneth Gergen apresenta três fatores que, para ele, são importantes para o sucesso do Projeto.

O primeiro deles é que há uma preparação anterior para os participantes. Eles devem estar disponíveis a experimentar uma nova forma de interação. É preciso haver abertura para perceber o outro como sendo passível de ser compreendido e apreciado, considerando que o outro tem algo que vale a pena ouvir. As pessoas recebem a garantia de que não vão passar por nenhuma situação em que se sintam desconfortáveis e os participantes se comprometem a não fazem julgamentos ou ofensas a seus oponentes.

O segundo fator importante é que, antes de entrar no tema sobre o qual divergem, os convidados participam de um jantar em que interagem e conversam sobre vários temas, exceto o assunto sobre o qual divergem. Os organizadores buscam estabelecer um clima de confiança e bem-estar que facilita a integração entre as pessoas e muitos podem se dar conta de que eles têm mais coisas em comum do que imaginavam. Isso pode fazer com que as polaridades sejam reduzidas e abrem possibilidades de conviver e conversar além e apesar das divergências.

O terceiro fator de sucesso do Projeto é que os participantes são convidados a contar um pouco da sua história de vida e a tratar o tema de maneira pessoal e afetiva.

Há pelo menos três razões pelas quais as expressões narrativas são desejáveis para o diálogo transformador. Primeiro, eles são facilmente compreensíveis: desde os primeiros anos, estamos expostos à história ou à forma narrativa, e estamos mais preparados para entender do que no caso de argumentos abstratos. Em segundo lugar, as histórias podem convidar a um envolvimento mais amplo do público do que as ideias abstratas. Ao ouvir histórias, geramos imagens, acompanhamos o desenrolar do drama, sofremos e celebramos com o orador. Pode-se rir ou chorar. Finalmente, a história pessoal tende a gerar aceitação em oposição à resistência (GERGEN, 2015, p.137, tradução nossa).

Esta experiência mostra como é possível criar e estabelecer relações amigáveis mesmo entre grupos com grande rivalidade, causa de muitos conflitos graves, inclusive assassinatos e guerras. O diálogo transformativo não envolve custos altos, não demanda tecnologia, nem anos 
de preparação. Além disso, é extremamente útil em nosso cotidiano, pois lidamos com pessoas diferentes e precisamos negociar opiniões e posicionamentos divergentes em vários momentos e contextos. Sempre podemos melhorar nossas formas de comunicação, estabelecendo conexões mais generativas para todos.

\section{Pensando a educação livre e inclusiva}

A escola é um espaço privilegiado para se explorar maneiras de se viver em comum pois, pela sua própria organização, ela já é uma comunidade de pessoas que não tem nada em comum e que convivem muitas horas por dia, por meses, anos e, às vezes, mais de uma década. A escola pública, um direito de todos é, por excelência, o espaço da diversidade.

A concepção e implementação de uma escola para todos é recente na história do Brasil. Tanto as legislações quanto os dados estatísticos da educação no país deixam evidente que, pouco a pouco, as escolas foram abrindo suas portas para acolher crianças e adolescentes que, décadas anteriores, jamais estariam ali ${ }^{5}$. As crianças chegam mais novas ${ }^{6} \mathrm{e}$ ficam cada vez mais horas na escola?.

\footnotetext{
${ }^{5} \mathrm{Um}$ exemplo disso são as legislações brasileiras que favoreceram a inclusão de pessoas com deficiência no ambiente escolar.

${ }^{6}$ Em 11 de novembro de 2009, a Emenda Constitucional 59 tornou a: "educação básica obrigatória e gratuita dos 4 (quatro) aos 17 (dezessete) anos de idade, assegurada inclusive sua oferta gratuita para todos os que a ela não tiveram acesso na idade própria" (BRASIL, 2009).

${ }^{7}$ A Lei de Diretrizes e Bases da Educação Nacional (BRASIL, 1996) indicou o aumento progressivo da jornada escolar para 7 horas diárias, bem como os Planos Nacionais de Educação de 2001-2010 (BRASIL, 2001) e 2014-2024 (BRASIL, 2014) que visam implementar a ampliação da jornada escolar nas escolas públicas de Educação Básica.
}

Periódico Horizontes - USF - Itatiba, SP - Brasil - e020034 
Gráfico 1: Gráfico da frequência escolar no Brasil entre 1984 e 2014

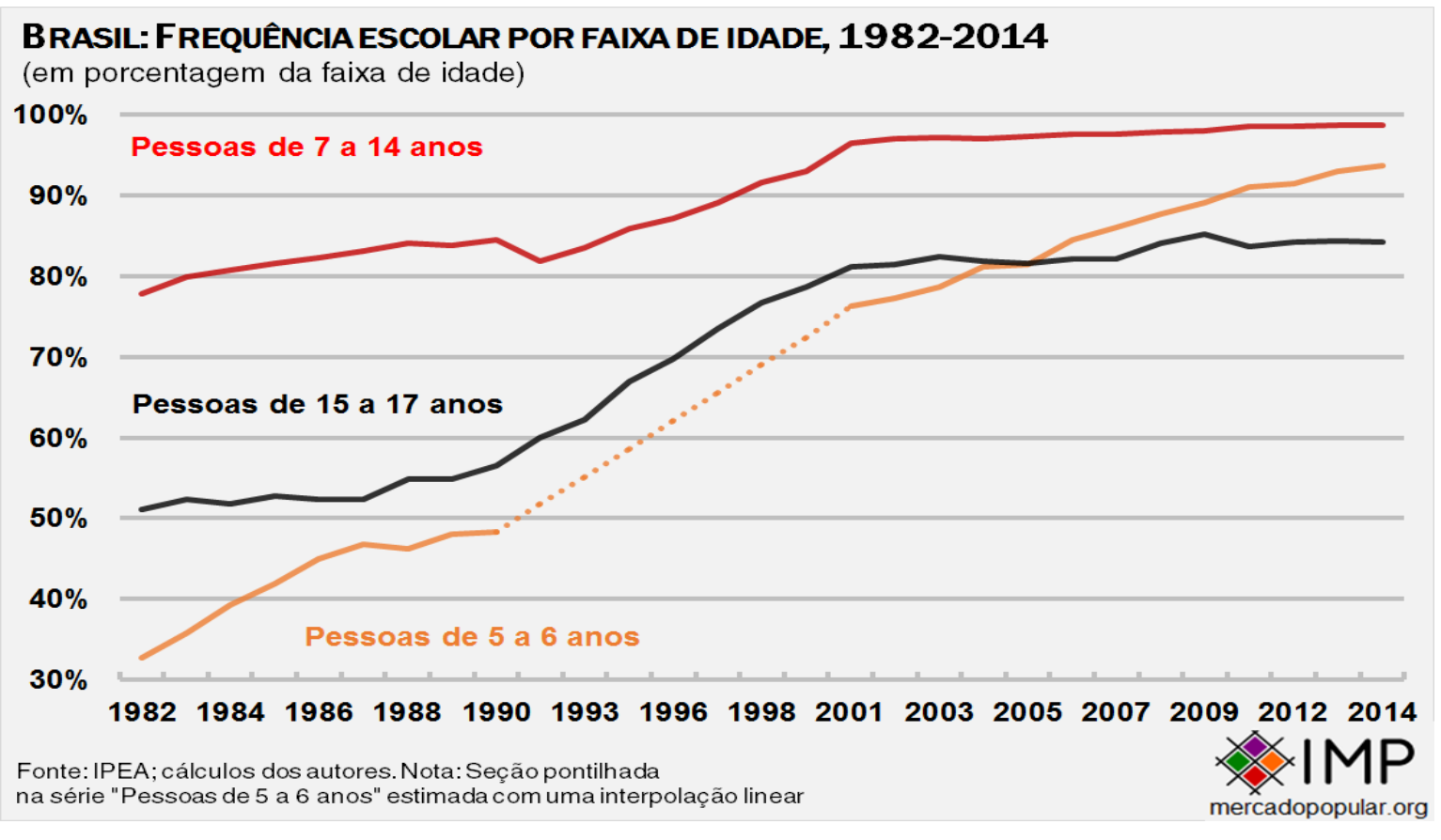

Fonte: Instituto Mercado Popular (2016) ${ }^{8}$

Assim como as escolas, o ambiente de trabalho, a vizinhança e até a família costuma reunir pessoas muito diferentes, pois nem sempre selecionamos as pessoas com as quais convivemos. Pode-se afirmar que, em última instância, todo e qualquer grupo é uma comunidade que não tem coisas em comum, já que os participantes de um grupo religioso podem divergir sobre política, sócios de um clube terem religiões diferentes etc. Isso é fato, mas dificilmente qualquer um destes grupos reuniria, com tanta proximidade, pessoas que tem religiões, valores, características, condições socioeconômicas, objetivos de vida e interesses tão distintos e por tanto tempo, como faz a escola, especialmente se ela for pública.

Mas, como já dissemos, nem sempre foi assim. Por muito tempo os professores não lidavam com tanta diversidade e os que não se ajustassem àquele modelo, cedo ou tarde, eram excluídos da instituição - pela evasão e/ou reprovação -, restando um grupo cada vez menos heterogêneo. Pode-se dizer que a função da escola, neste momento, era mais reprovar e

\footnotetext{
${ }^{8}$ DUQUE, D; OLIVEIRA, P. C. Raio-x da educação brasileira: o folclore dos $10 \%$ do PIB. 30 setembro de 2016. Instituto Mercado Popular. Disponível em: http://mercadopopular.org/2016/09/raio-x-da-educacao-brasileira-porque-10do-pib-para-a-educacao-e-folclore/. Acesso em 11 abril 2019.
} 
selecionar, que ensinar ${ }^{9}$. Alunos que aprendiam e tinham bom comportamento ficavam, os que não aprendiam e/ou eram "problemáticos" eram excluídos. Simples assim.

O professor que chega hoje em uma sala de aula encontra realidades e desafios muito diferentes daqueles que deram aulas em décadas anteriores e, portanto, precisa de uma preparação muito distinta. A sociedade mudou, os alunos são outros, os objetivos da educação avançaram e, por mais saudosista que sejamos, há que se reconhecer que hoje a escola é muito menos excludente e nos cabe criar formas de viver em comum.

O professor da atualidade tem o desafio de ensinar alunos com dificuldades de aprendizagem, com deficiências - diagnosticadas ou não - e, muitas vezes, completamente desinteressados. Essa é uma realidade. Por outro lado, podemos pensar que ensinar alunos que tem facilidade, interesse e todas as condições de aprendizagem não é desafio para ninguém. Estes alunos aprendem até mesmo sem professor. O bom profissional se constrói com os alunos difíceis e desinteressados. Claro que seria muito mais fácil se os professores fossem mais valorizados, os alunos mais dedicados, as famílias participativas e as condições de trabalho mais adequadas. Em não sendo, ainda há muito que o educador possa fazer. Do ponto de vista relacional, não se trata de pensar que é um trabalho de via única. Não buscamos heróis. O desafio é justamente conseguir estabelecer relações, vínculos e compromissos com os difíceis, os antagonistas, os discordantes. Isto é criar comunidade dos que não tem nada em comum.

Reitero a ideia de que a escola é um local privilegiado para o desenvolvimento de práticas de convivência com a diversidade. Não digo aqui que precisamos "aprender" a viver em comunidade de desiguais, porque estaria subentendido que esse modelo exista e nos cabe apenas replicá-lo. Não creio nisso. Penso que o caminho não existe. É preciso construí-lo. Não há modelos prontos a serem transmitidos. Nossos antepassados não vivenciaram as demandas do mundo atual globalizado e inclusivo. Nos cabe criar as nossas próprias alternativas, experimentálas, revisá-las e ir sempre fazendo ajustes de acordo com as necessidades de cada realidade. Propostas como o diálogo transformativo, a presença radical, a postura de não-saber, a responsabilidade relacional; a experiência de projetos como o de Conversações Públicas podem ser muito úteis para nossa vida pessoal, profissional e para serem aplicados nas escolas. No

\footnotetext{
${ }^{9}$ O livro Cuidado Escola publicado em 1980 denuncia o quanto a educação, por muito tempo, tinha uma função selecionadora, preparando mão de obra para o mercado de trabalho (HARPER et al., 2000).
} 
entanto, não pensemos que se trata de uma transposição simples e direta. São inspirações. Iniciativas que nos ampliam o olhar e a esperança. Mas, de fato, cada escola precisa construir suas próprias práticas a partir de iniciativas coletivas, que reúnam professores, gestores, estudantes, familiares e comunidade. O primeiro desafio talvez seja exatamente este: o de criar grupos que, juntos, se comprometam a construir uma educação para a inclusão e para a liberdade.

\section{Considerações finais}

O Construcionismo Social apresenta uma forma diversa de perceber o mundo e os seres humanos que não necessariamente seja melhor ou mais verdadeira que as demais. É outra forma possível, que pode gerar outras realidades e outros resultados. Nossa proposta aqui foi explorar um pouco estas ideias e como acreditamos que elas podem nos levar a uma convivência mais inclusiva e, pari passu, com maior liberdade. Milênios de anos de existência humana e incontáveis avanços tecnológicos não foram suficientes para estabelecer uma convivência generativa com os nossos semelhantes e nem com o meio ambiente. Nossa aposta é que uma visão relacional de nós mesmos pode nos ajudar neste intento de criar uma convivência mais harmônica e promissora para todos.

A inclusão, o convívio com as diferenças não é um processo biológico, não vai se dar por imposição de uma lei. É um processo de aprendizado. Nossas percepções do mundo, de nós mesmos e dos outros são construções sociais. Podemos alterar estas percepções radicalmente, não sozinhos, mas sempre de maneira coletiva. Para isso, dependemos de uma nova educação, não para a repetição, para a obediência e para a concordância. Uma educação para estar junto, para conviver, para lidar com as infinitas, criativas e diferentes possibilidades de ser e estar no mundo.

Acreditamos que o diálogo transformativo pode nos abrir possibilidades de conversação que permitam olhar de maneira diferente para as dificuldades, ampliando nosso campo de compreensão e nossas possibilidades de ação. Não se trata de uma resposta simples. O diálogo demanda, antes de tudo, uma abertura ao outro, ao encontro, a considerar perspectivas e valores que se contrapõem ao que defendemos com todas as nossas forças e conviç̧ões. Não é 
uma tarefa fácil. Nos coloca diante dos nossos temores, de valores que nem sempre aceitamos que possam ser confrontados ou questionados. Nos exige a humildade de aceitar que o outro tem o direito de defender e sustentar seus valores e crenças, tanto quanto nós.

Muitas vezes se confunde o Construcionismo com um completo relativismo, o que é um grande equívoco. Não significa que crimes não devam ser punidos, que opiniões e atitudes preconceituosas e desrespeitosas não devam ser proibidas e devidamente penalizadas. Significa que, na maioria das vezes, podemos julgar menos e conversar mais. Podemos compreender que, mesmo atitudes abomináveis e perversas, são absolutamente humanas e, como tal, dizem respeito a todos. Afinal, por mais que os outros nos pareçam estranhos, desagradáveis e perigosos, eles nos constituem e nós os constituímos. Não estamos sós nessa jornada. A aventura é coletiva e exige de nós coragem para enfrentar os nossos medos e convicção que a diversidade humana é uma riqueza que devemos conhecer, reconhecer e celebrar.

\section{Referências}

ANDERSON, H.; CHAVESTE, R.; MOLINA, P. Harlene: conversaciones interrompidas. Ohio, EUA: Taos Institute Publications, 2019.

BAUMAN, Z. Identidade: entrevista a Benedetto Vecchi. Rio de Janeiro: Jorge Zahar Ed., 2005.

BIESTA, G. J. J. The community of those who have nothing in common: education and the language of responsibility. Interchange, Suiça, v.35/3, p.307-324, 2004.

BITTENCOURT, J. B. M. "O inferno são os outros": uma análise sobre o medo do estranho na cidade de Fortaleza (CE). Revista Mal-Estar e Subjetividade. Fortaleza, v.IX, n.1, p.161-185, mar.2009.

BRASIL. Lei n. 9.394, de 23 de dezembro de 1996. Estabelece as diretrizes e bases da educação nacional. Disponível em: http://www.planalto.gov.br/ccivil_03/LEIS/L9394.htm. Acesso em: 11 abr. 2019.

BRASIL. Lei n. 10.179 de janeiro de 2001. Aprova o Plano Nacional de Educação e dá outras providências. Disponível em: http://www.planalto.gov.br/ccivil_03/leis/leis_2001/l10172.htm. Acesso em: 11 abr. 2019.

BRASIL. Emenda Constitucional no 59, de 11 de novembro de 2009. Disponível em: http://www.planalto.gov.br/ccivil_03/Constituicao/Emendas/Emc/emc59.htm. Acesso em: 26 mar. 2019.

Periódico Horizontes - USF - Itatiba, SP - Brasil - e020034 
BRASIL. Lei 13.005, de 25 de junho de 2014. Aprova o Plano Nacional de Educação - PNE e dá outras providências. Disponível em: http://pne.mec.gov.br/18-planos-subnacionais-deeducacao/543-plano-nacional-de-educacao-lei-n-13-005-2014. Acesso em: 14 abr. 2019.

COSTA, J. F. A devoração da esperança no próximo. São Paulo: Jornal Folha de São Paulo: Caderno Mais. São Paulo, domingo, 22 de setembro de 1996, s.d. Disponível em: https://www1.folha.uol.com.br/fsp/1996/9/22/mais!/11.html. Acesso em: 19 mar. 2019.

ESGOTAMENTO dos recursos naturais. Revista Superinteressante. 22 maio 2012. Disponível em: https://super.abril.com.br/ciencia/esgotamento-dos-recursos-naturais/. Acesso em: 08 abr. 2019.

FREIRE, S. Um olhar sobre a inclusão. Revista da Educação. v.16, n.1, p.5-20, 2008.

GERGEN, K. J. Construccionismo social, aportes para el debate y la práctica. Bogotá: Universidad de los Andes, Facultad de Ciencias Sociales, Departamento de Psicología, CESO, Ediciones Uniandes, 2007.

GERGEN, K. J. An invitation to social construction. 3.ed. London: Sage, 2015.

GERGEN, K. J. El ser relacional: más allá de yo y de la comunidad. Bilbao: Editorial Desclée de Brouwer, 2016.

GERGEN, K. J. GERGEN, M. Reflexiones sobre la construcción social. Barcelona, Paidós, 2011.

HARPER, B. et al. Cuidado Escola! desigualdade, domesticação e algumas saídas. 36.ed. São Paulo: Brasiliense, 2000.

MCNAMEE, S. Presencia radical: alternativas para el estado terapéutico. European Journal of Psychotherapy and Counselling. v.17, n.4, p.1-10, 2015.

OS 26 mais ricos do mundo concentram a mesma riqueza dos 3,8 bilhões mais pobres. Jornal 0 GLOBO. 22 jan. 2019. Disponível em: https://oglobo.globo.com/economia/os-26-mais-ricos-domundo-concentram-mesma-riqueza-dos-38-bilhoes-mais-pobres-23391701. Acesso em: 08 abr. 2019.

SAMPSON, E. Possessive individualism and self-contained ideal. In: SAMPSON, E. E. Celebration the other: a dialogic account of human nature. Chagrin Falls, Ohio, USA: Taos Institute Publications, 2008, p. 31-41.

SAMPSON, E. E. Celebration the other: the dialogic turn. In: SAMPSON, E. E. Celebration the other: a dialogic account of human nature. Chagrin Falls, Ohio, USA: Taos Institute Publications, 2008, p. 31-41.

p.97-109. 
SPINK, J. M.; MEDRADO, B.; MÉLLO, R. P. Vinte e cinco anos nos rastros de trilhas, riscos e produções acadêmicas e situadas. In: SPINK, M. J. P.; BRIGAGÃO, J. I. M.; NASCIMENTO, V. L. V.; CORDEIRO, M. P.(orgs). A produção de informação na pesquisa social: compartilhando ferramentas. Rio de Janeiro: Centro Edelstein de Pesquisas sociais, 2014, p.13-30.

\section{AGRADECIMENTOS}

Agradeço a colaboração do Grupo de Estudos em Construcionismo Social (Jaqueline, Luana, Pedro, Rita, Sáhira e Uyrá) por suas leituras, comentários e considerações a respeito deste e outros textos e também aos aprendizados sobre o tema com Rocío Chaveste, Papusa Molina e Sheila McNamee.

Recebido em abril 2019.

Aprovado em janeiro 2020. 